\title{
Isolated persistent left superior vena cava in a young adult without cardiac disease
}

\author{
Satyajeet Sahoo, Manoj Kumar Panigrahi \\ All India Institute of Medical Sciences, Bhubaneswar, India
}

A 30-year-old non-diabetic, normotensive male presented to our outpatient department with intermittent left-sided chest pain that had bothered him for the last 3 years. The pain was insidious, non-pleuritic, radiating to the back, mild in intensity and not aggravated by exertion. The pain was not relieved by analgesics or proton pump inhibitors (which he was prescribed during his previous visits). There was no breathlessness, cough, haemoptysis, palpitations, paroxysmal nocturnal dyspnoea, heartburn, regurgitation or weight loss. On examination, the patient had a pulse rate of $86 / \mathrm{min}$ which was regular and equally palpable in all four limbs. Blood pressure was recorded as $110 / 70 \mathrm{~mm} \mathrm{Hg}$ in all four limbs. He was maintaining a saturation of 99\% at room air. ECG showed normal sinus rhythm. Examination of the chest and the cardiovascular system was normal. Chest radiograph was normal (Figure 1A). Transthoracic echocardiography showed a dilated coronary sinus with presence of a left superior vena cava (SVC). Computed tomography (CT) scan of thorax with intravenous contrast confirmed the presence of a left-sided SVC (Figure 1B, C) draining into the coronary sinus with subsequent drainage into the right atrium. A detailed cardiac workup ruled out the presence of any associated cardiac disease.

Persistent left-sided superior vena cava (PLSVC) is the most commonly encountered thoracic venous anomaly with a prevalence of $0.5 \%$ in the general population [1]. It is usually a fortuitous finding among cardiovascular diseases including atrial septal defect, coarctation of aorta, bicuspid aortic valve or conduction abnormalities. Although commonly encountered with congenital heart diseases, it is extremely rare in patients without evidence of any cardiac disease [2]. In this condition the normal right sided superior vena cava may be reduced in size or may be completely absent. In $80-90 \%$ of cases, the PLSVC duplicates in the presence of a co-existing right-sided SVC. At rest, however, it is isolated [1]. PLSVC draining into the left atrium can result in a right-to-left shunt leading to hypoxemia or embolic clinical consequences like stroke, renal infarcts and brain abscess $[3,4]$. Although the presence of duplicate PLSVC draining into the right atrium has no adverse hemodynamic effects, it is of clinical relevance. Left sided central venous line insertion can be misleading and inadvertent coronary sinus cannulation can lead to cardiac perforation as well. PLSVC has also been associated with arrhythmias. One should also be careful enough to differentiate it from partial anomalous pulmonary venous drainage of the left upper lobe. Even though contrast enhanced magnetic resonance angiography has been considered as the investigative examination of choice, echocardiography and CT of the thorax can both accurately diagnose the presence of PLSVC.
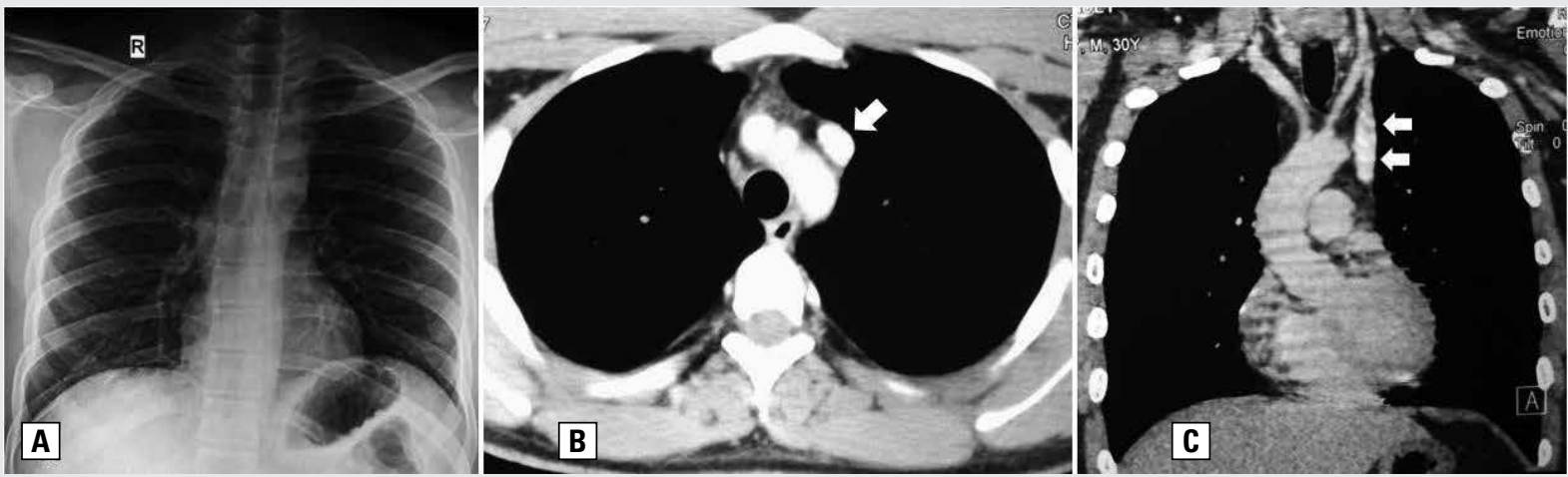

Figure 1. A. Frontal chest radiograph showing normal cardio-mediastinal contours; B. Axial section of CT thorax at (mediastinal window) showing left sided superior vena cava (arrow); C. Coronal reformatted image confirming its presence on left side (arrows)

Address for correspondence: Manoj Kumar Panigrahi, Department of Pulmonary Medicine \& Critical Care, All India Institute of Medical Sciences, Bhubaneswar, India; e-mail: manoj_kp99@rediffmail.com

DOI: 10.5603/ARM.2019.0068

Received: 12.10.2019

Copyright (C) 2019 PTChP

ISSN 2451-4934

Conflict of interest: none declared 


\section{References:}

1. Irwin RB, Greaves M, Schmitt M. Left superior vena cava: revisited. Eur Heart J Cardiovasc Imaging. 2012; 13(4): 284-291, doi: 10.1093/ehjci/jes017, indexed in Pubmed: 22301985.

2. Pálinkás A, Nagy E, Forster T, et al. A case of absent right and persistent left superior vena cava: echocardiographic diagnosis. Orv Hetil. 2005; 146(7): 319-322, indexed in Pubmed: 15782795.

3. Barba T, Karsenty J, Boussel L, et al. Brain abscess associated with persistent left superior vena cava in a 58-year-old man. BMJ Case Rep. 2013; 2013, doi: 10.1136/bcr-2013-009017, indexed in Pubmed: 23513026.

4. Bola SS, Narang I. An elusive cause of hypoxaemia in a paediatric patient. BMJ Case Rep. 2014; 2014, doi: 10.1136/bcr-2013-201819, indexed in Pubmed: 24859546. 